\title{
Evaluation of an aldose reductase inhibitor on lens metabolism, ATPases and antioxidative defense in streptozotocin-diabetic rats: an intervention study
}

\author{
I. G. Obrosova, L. Fathallah \\ Division of Endocrinology and Metabolism, Department of Internal Medicine, University of Michigan Medical Center, \\ Ann Arbor, Michigan, USA
}

\begin{abstract}
Aims/hypothesis. Aldose reductase inhibitors (ARIs) prevent biochemical abnormalities associated with diabetic complications. We evaluated whether a short-term intervention with an adequate dose of ARI, introduced at the very early, precataractous stage, reversed diabetes-induced metabolic imbalances, down-regulation of ATPases and oxidative stress in the lens.

Methods. The groups included mature control and streptozotocin-diabetic rats treated with or without ARI sorbinil $\left(65 \mathrm{mg} \cdot \mathrm{kg}^{-1} \cdot \mathrm{day}^{-1}\right.$, in the diet, for 2 weeks after 4 weeks of untreated diabetes). Free cytosolic $\mathrm{NAD}^{+}: \mathrm{NADH}$ and $\mathrm{NADP}^{+}: \mathrm{NADPH}$ ratios were calculated from the lactate dehydrogenase and malic enzyme systems. Concentrations of metabolites and adenine nucleotides, $\mathrm{Na}^{+} / \mathrm{K}^{+}$-ATPase, $\mathrm{H}^{+}$ATPase and $\mathrm{Ca}^{++}$-independent $\mathrm{Mg}^{++}$-ATPase activities and variables of oxidative stress were measured in individual lenses.

Results. Sorbinil treatment essentially corrected diabetes-induced sorbitol and fructose accumulation, myo-inositol depletion, decrease in free cytosolic
\end{abstract}

$\mathrm{NAD}^{+}: \mathrm{NADH}$ ratio and energy deficiency. Malondialdehyde accumulation, reduced glutathione depletion and the increase in oxidized glutathione:reduced glutathione ratio were partially corrected. Free cytosolic $\mathrm{NADP}^{+}$:NADPH ratio and 4-hydroxyalkenal concentrations were similarly increased in diabetic rats treated with or without ARI. Sorbinil did not counteract diabetes-induced down-regulation of the three ATPase activities.

Conclusion/interpretation. All biochemical changes assessed in our study are known to be prevented by ARIs. Despite the essential normalization of the sorbitol pathway activity, only part of them were, however, reversed by the ARI treatment introduced at the very early, i. e. precataractous, stage of diabetes. Therefore, intervention studies can easily underestimate the importance of aldose reductase in the pathogenesis of diabetic complications and should be interpreted with caution. [Diabetologia (2000) 43:1048-1055]

Keywords Aldose reductase, ATPase activities, energy metabolism, lens, NAD(P)-redox state, oxidative stress, rat, reversal study, sorbinil, streptozotocin-diabetes
Received: 24 February 2000 and in revised form: 6 April 2000

Corresponding author: Dr. I. Obrosova, Division of Endocrinology and Metabolism, Department of Internal Medicine, University of Michigan Medical Center, 1150 West Medical Center Drive, MSRB II, Rm 5570, Ann Arbor, Michigan 48109-0354, USA

Abbreviations: AR: Aldose reductase, ARI: aldose reductase inhibitor, 4-HA: 4-hydroxyalkenals, GSSG: oxidized glutathione, GSH: reduced glutathione, MDA: malondialdehyde, $\mathrm{P}_{\mathrm{i}}$ : inorganic phosphate, $\mathrm{SDH}$ : sorbitol dehydrogenase
The consequences of increased aldose reductase (AR) activity in tissue-sites for diabetic complications include down-regulation of membrane transporters and osmolyte depletion $[1,2]$, impaired ion homeostasis $[1,3]$, energy deficiency $[4,5]$, NADredox and NADP-redox changes [5], oxidative stress [6-8], protein kinase $\mathrm{C}$ activation $[9,10]$, accumulation of advanced glycation end-products [11, 12], impaired neurotrophism $[13,14]$, up-regulation of vascular endothelial growth factor [15] and other imbalances. Numerous studies in the animals models of di- 
abetes and galactose feeding indicate that these biochemical changes and, most importantly, their outcome, i.e. diabetic complications, are prevented by structurally different AR inhibitors (ARIs) [1-6, $8-19]$. In contrast, the results of clinical trials of ARIs on diabetic neuropathy [20] and retinopathy [21] were disappointing and created a number of questions regarding the trials' design, adequacy of the ARI doses as well as applicability of the AR concept to diabetic complications in humans in general and reversibility of the early and later stages of these complications.

During the last 5 years, a number of experimental studies were conducted to find out if the pathological process can be stopped and reversed after the whole spectrum of biochemical, functional and morphological changes has been initiated. The findings of at least two groups $[17,22]$ indicate that diabetes-induced neurovascular dysfunction, nerve conduction deficit and metabolic imbalances, characteristic for early experimental diabetic neuropathy, can be corrected by a very short (2 week) treatment with an adequate dose of ARI, i. e. the dose that completely blocked diabetes-associated increase in the sorbitol pathway activity. Retinal changes seemed, however, less prone to normalization. In particular, it was found that a 12month treatment with an adequate dose of ARI did not correct early vascular abnormalities characteristic for diabetes-like retinopathy [23]. The results of longer ARI treatment from the same group [24] as well as the experiments with galactose withdrawal in the galactosaemic dog model (Kador et al., unpublished) provided, however, the evidence that the reversal of retinal vascular changes, at least at the stage of background retinopathy, can be achieved in principle.

The lens offers a number of advantages for studying AR-mediated metabolic imbalances because all major diabetes-associated metabolic changes, i.e. sorbitol pathway intermediate accumulation $[6$, 25-27], osmolyte depletion [26], down-regulation of ATPases [28, 29], energy deficiency [4, 5], NADredox and NADP-redox changes [5], antioxidant loss [6] and activation of lipid peroxidation [27] are clearly manifested in early diabetes. All these imbalances have been implicated in initiation (sorbitol accumulation) or progression of diabetic cataract formation and have been found preventable by ARIs [1, 4-6, 30]. The purpose of our study was to evaluate whether these diabetes-associated biochemical abnormalities can be reversed by a short-treatment with an adequate dose of ARI, introduced at the precataractous stage.

\section{Materials and methods}

The experiments were done in accordance with regulations specified by The Guiding Principles in the Care and Use of Animals (DHEW Publication, NIH 80-23) and the University of Michigan Protocol for Animal Studies.

Animals. Male Wistar rats (Charles River, Wilmington, Mass., USA), body weight 250-300 g, were fed a standard rat chow diet (ICN Biomedicals, Cleveland, Ohio, USA) and had free access to water. Diabetes was induced by a single injection of streptozotocin (Upjohn, Kalamazoo, Mich., USA, $55 \mathrm{mg} / \mathrm{kg}$ body weight, i.p.). Blood samples for glucose measurements were taken from the tail vein about $48 \mathrm{~h}$ after streptozotocin injection and the day before the rats were killed. Rats with blood glucose concentrations of $13.9 \mathrm{mmol} / \mathrm{l}$ or more were considered diabetic. The experimental groups included control and diabetic rats treated with or without ARI sorbinil (Pfizer, $65 \mathrm{mg} \cdot \mathrm{kg}^{-1} \cdot \mathrm{day}^{-1}$, in the diet, for 2 weeks after 4 weeks of untreated diabetes).

Experimental procedure. Rats were sedated with carbon dioxide and killed by cervical dislocation. Both lenses were dissected by posterior incision, carefully separated from accompanying aqueous and vitreous humors, and frozen in liquid nitrogen. One lens from each rat was used for measurements of sorbitol pathway intermediates, malondialdehyde (MDA), MDA plus 4-hydroxyalkenals (4-HA) and total and ouabain-insensitive $\mathrm{Na}^{+} / \mathrm{K}^{+}$-ATPase activities. The second lens was used for measurements of reduced glutathione (GSH), oxidized glutathione (GSSG), pyruvate, lactate, malate, ATP, ADP and AMP. A separate set of lenses was used for assessment of $\mathrm{H}^{+}$ATPase and $\mathrm{Ca}^{++}$-independent $\mathrm{Mg}^{++}$-stimulated ATPase activities.

Biochemical measurements. Concentrations of glucose, sorbitol, fructose, GSH, GSSG, MDA, MDA plus 4-HA, pyruvate, lactate, malate and adenine nucleotides were assayed as described [26, 27, 31-33]. Free cytosolic $\mathrm{NAD}^{+}: \mathrm{NADH}$ and $\mathrm{NADP}^{+}: \mathrm{NADPH}$ were calculated from the steady-state metabolite concentrations and equilibrium constants of the lactate dehydrogenase and malic enzyme systems [34, 35]. For measurements of $\mathrm{Na}^{+} / \mathrm{K}^{+}$-ATPase, $\mathrm{H}^{+}$-ATPase and $\mathrm{Ca}^{++}$-independent $\mathrm{Mg}^{++}$-stimulated ATPase activities, lenses were homogenized in $1.5 \mathrm{ml} 0.1 \mathrm{~mol} / \mathrm{l}$ sodium-phosphate buffer, $\mathrm{pH}$ 6.5. The homogenate was centrifuged at $3000 \mathrm{~g}$ to precipitate large particles and cell debris. The analytical mixture for $\mathrm{Na}^{+} /$ $\mathrm{K}^{+}$-ATPase contained $0.15 \mathrm{mmol} / \mathrm{l} \mathrm{NADH}, 1 \mathrm{mmol} / \mathrm{l}$ phosphoenolpyruvate, $1 \mathrm{mmol} / \mathrm{l}$ TRIS-ATP, $2 \mathrm{U}$ of pyruvate kinase and $5 \mathrm{U}$ of lactate dehydrogenase in $0.9 \mathrm{ml}$ buffer containing $100 \mathrm{mmol} / 1 \mathrm{NaCl}, 10 \mathrm{mmol} / \mathrm{l} \mathrm{KCI}, 2.5 \mathrm{mmol} / \mathrm{l} \mathrm{MgCl}_{2}$ and $30 \mathrm{mmol} / \mathrm{l}$ imidazole- $\mathrm{HCl}, \mathrm{pH}$ 7.3. The reaction was initiated by addition of $0.1 \mathrm{ml}$ supernatant and the total activity was measured spectrophotometrically for $15 \mathrm{~min}$ by monitoring a decrease in absorbance at $340 \mathrm{~nm}$ due to oxidation of NADH to NAD, stochiometric to hydrolysis of ATP to ADP and inorganic phosphate $\left(\mathrm{P}_{\mathrm{i}}\right)$. Then $0.02 \mathrm{ml}$ of $25 \mathrm{mmol} / \mathrm{l}$ ouabain was added and the reaction was followed for another $15 \mathrm{~min}$. Ouabain-sensitive $\mathrm{Na}^{+} / \mathrm{K}^{+}$-ATPase activity was calculated as the difference between total and ouabain-insensitive $\mathrm{Na}^{+} / \mathrm{K}^{+}$-ATPase activities. For measurements of $\mathrm{H}^{+}$-ATPase and $\mathrm{Ca}^{++}$-independent $\mathrm{Mg}^{++}$-stimulated ATPase activities, the lenses were homogenized in $1 \mathrm{ml}$ buffer containing $10 \mathrm{mmol} / 1 \mathrm{HEPES}$, $100 \mathrm{mmol} / \mathrm{l} \mathrm{KCl}$ and $0.1 \mathrm{mmol} / \mathrm{l}$ EGTA, $\mathrm{pH}$ 7.4. The homogenates were centrifuged at $3000 \mathrm{~g}$ for $10 \mathrm{~min}$. Then $\mathrm{H}^{+}$-ATPase activity was assayed in the supernatant fractions as described 
[36]. For measurements of $\mathrm{Ca}^{++}$-independent $\mathrm{Mg}^{++}$-stimulated ATPase activity, $0.25 \mathrm{mmol} / 1 \mathrm{MgCl}_{2}$ was added to the analytical mixture used for $\mathrm{H}^{+}$-ATPase [36]. The $\mathrm{Ca}^{++}$-independent $\mathrm{Mg}^{++}$-stimulated ATPase activity was calculated as the difference between total $\mathrm{Ca}^{++}$-independent $\mathrm{Mg}^{++}$-stimulated ATPase plus $\mathrm{H}^{+}$-ATPase activity and $\mathrm{H}^{+}$-ATPase activity.

Statistical analysis. The results are expressed as means \pm SEM. Data were subjected to equality of variance $F$ test and then to $\log$ transformation, if necessary, before one-way analysis of variance. When overall significance $(p<0.05)$ was attained, individual between-group comparisons were made using the Student-Newman-Keuls multiple range test. Significance was defined at $p 0.05$ or less. When between-group variance differences could not be normalized by log transformation, the data were analysed by the non-parametric Kruskal-Wallis one-way analysis of variance, followed by Fisher's PLSD test for multiple comparisons.

\section{Results}

The final body weights were lower in diabetic rats than in controls $(300.1 \pm 11.4$ vs $428.3 \pm 4.6 \mathrm{~g}$, $p<0.01)$. The initial body weights were similar in control and diabetic groups. No difference was found between final body weights in diabetic rats treated with ARI (307.8 $\pm 16.8 \mathrm{~g})$ and the untreated group.

Blood glucose concentration was increased 5.7fold in diabetic rats compared with controls $(18.1 \pm 0.6$ vs $3.2 \pm 0.1 \mathrm{mmol} / 1, p<0.01)$ and was not affected by ARI treatment $(18.5 \pm 0.6 \mathrm{mmol} / \mathrm{l})$.

Lens glucose, sorbitol and fructose concentrations were 9.1-fold, 120 -fold, and 9.4-fold higher in diabetic rats than controls (Table 1 ). Glucose concentrations were similar in diabetic rats treated with or without ARI. Sorbitol and fructose concentrations in diabetic rats were essentially normalized by the ARI treatment. Lens myo-inositol concentration was decreased 23.4-fold in diabetic rats compared with controls. This decrease was corrected by the ARI treatment.

Lens pyruvate and malate concentrations were decreased 1.7-fold and 1.8-fold in diabetic rats compared with controls (Table 2) and the decrease in both concentrations was corrected by the ARI treatment. Lens lactate concentrations were similar among the experimental groups. Free cytosolic $\mathrm{NAD}^{+}: \mathrm{NADH}$ ratio was 2.5 -fold lower in diabetic rats than in controls and this decrease was corrected by the ARI treatment. Free cytosolic NADP ${ }^{+}$NADPH ratios were similarly decreased in untreated and ARI-treated diabetic rats compared with controls.

Lens ATP concentration was 1.6-fold lower in diabetic rats than in controls whereas ADP and AMP concentrations were 1.6-fold and 2-fold higher (Table 3). Diabetes-induced decrease in ATP concentration was corrected by the ARI treatment whereas ADP and AMP concentrations tended to decrease being not significantly different from either the un-
Table 1. Sorbitol pathway intermediate and myo-inositol concentrations (nmol/lens) in control and diabetic rats treated with or without ARI $(n=8)$

\begin{tabular}{llcl}
\hline & Control & Diabetic & Diabetic + ARI \\
\hline Glucose & $18.9 \pm 2.2$ & $172 \pm 24^{\mathrm{a}}$ & $261 \pm 33^{\mathrm{a}}$ \\
Sorbitol & $13.3 \pm 2.8$ & $1594 \pm 152^{\mathrm{a}}$ & $33.8 \pm 7.7^{\mathrm{b}}$ \\
Fructose & $21.0 \pm 2.3$ & $197 \pm 19^{\mathrm{a}}$ & $37.0 \pm 6.4^{\mathrm{b}}$ \\
myo-Inositol & $63.2 \pm 2.7$ & $2.7 \pm 1.7^{\mathrm{a}}$ & $67.5 \pm 23.8^{\mathrm{b}}$ \\
\hline
\end{tabular}

${ }^{a}$ Significantly different compared with controls $(p<0.01)$;

$\mathrm{b}$ significantly different compared with untreated diabetic rats $(p<0.01)$

Table 2. Pyruvate, lactate and malate concentrations (nmol/ lens) and free cytosolic $\mathrm{NAD}^{+}: \mathrm{NADH}$ and $\mathrm{NADP}^{+}$: $\mathrm{NADPH}$ ratios in lens in control and diabetic rats treated with or without ARI $(n=7-8)$

\begin{tabular}{lccc}
\hline & Control & Diabetic & Diabetic + ARI \\
\hline Pyruvate & $6.7 \pm 0.7$ & $3.9 \pm 0.6^{\mathrm{a}}$ & $7.5 \pm 1.0^{\mathrm{c}}$ \\
Lactate & $310 \pm 59$ & $436 \pm 66$ & $487 \pm 59$ \\
Malate & $3.8 \pm 1.3$ & $2.1 \pm 0.7^{\mathrm{a}}$ & $3.9 \pm 1.5^{\mathrm{c}}$ \\
$\mathrm{NAD}^{+}: \mathrm{NADH}$ & $194 \pm 26$ & $79 \pm 6^{\mathrm{b}}$ & $155 \pm 18^{\mathrm{c}}$ \\
$\mathrm{NADP}^{+}: \mathrm{NADPH}$ & $0.041 \pm 0.005$ & $0.061 \pm 0.007^{\mathrm{a}}$ & $0.062 \pm 0.007^{\mathrm{a}}$ \\
\hline
\end{tabular}

a,b Significantly different compared with controls $(p<0.05$ and $<0.01$, respectively); ${ }^{\mathrm{c}}$ significantly different compared with untreated diabetic group $(p<0.01)$

Table 3. Lens energy status in control and diabetic rats treated with or without ARI $(n=6-8)$

\begin{tabular}{lccc}
\hline & Control & Diabetic & Diabetic + ARI \\
\hline ATP & $133 \pm 18$ & $84 \pm 9^{\mathrm{a}}$ & $134 \pm 19$ \\
ADP & $14.7 \pm 4.3$ & $23.6 \pm 7.5^{\mathrm{a}}$ & $20.8 \pm 3.6$ \\
AMP & $3.9 \pm 0.4$ & $6.6 \pm 0.8^{\mathrm{b}}$ & $5.0 \pm 0.5$ \\
ATP : ADP & $7.7 \pm 2.3$ & $4.0 \pm 1.5^{\mathrm{a}}$ & $6.8 \pm 1.1^{\mathrm{c}}$ \\
Adenylate charge & $0.91 \pm 0.01$ & $0.84 \pm 0.01^{\mathrm{b}}$ & $0.90 \pm 0.01^{\mathrm{d}}$ \\
\hline
\end{tabular}

ATP, ADP, AMP concentrations are expressed in nmol/lens a,b Significantly different compared with controls $(p<0.05$ and $<0.01$, respectively); ${ }^{\mathrm{c}, \mathrm{d}}$ significantly different compared with untreated diabetic group ( $p<0.05$ and $<0.01$, respectively)

treated diabetic group or controls. The ATP:ADP ratio and adenylate energy charge were 1.9-fold and 1.1-fold lower in diabetic rats than in controls. Both variables were corrected by ARI.

Total, ouabain-insensitive and ouabain-sensitive ATPase activities were 1.7-fold, 1.6-fold and 1.7-fold lower in diabetic rats than controls and none of these activities were affected by ARI (Fig. 1). In a similar fashion, $\mathrm{H}^{+}$-ATPase activities were 2.3-fold and 1.5fold lower in untreated and ARI-treated diabetic rats than controls (Fig.2). The $\mathrm{Ca}^{++}$-independent $\mathrm{Mg}^{++}$-stimulated ATPase activity was decreased 3.4fold in diabetic rats compared with controls. This activity tended to increase with the ARI treatment but the difference with the untreated diabetic group did not achieve statistical significance. 


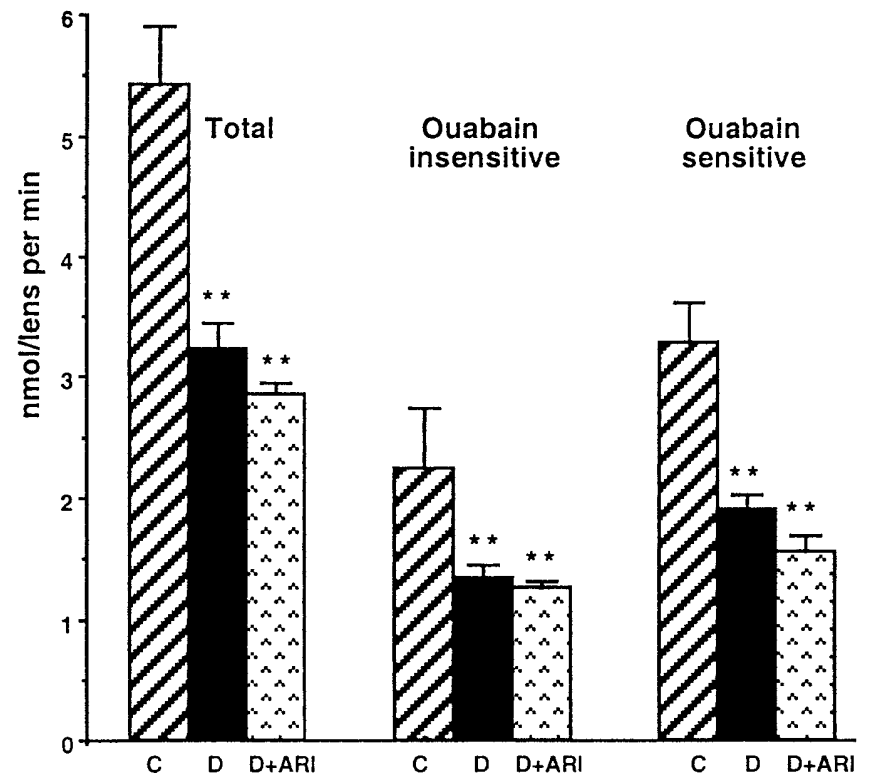

Fig. 1. Lens total, ouabain-insensitive and ouabain-sensitive $\mathrm{Na}^{+} / \mathrm{K}^{+}$-ATPase activities in control (C) and diabetic (D) rats treated with or without ARI (means \pm SEM, $n=8-10)$. **; significantly different vs controls $(p<0.01)$

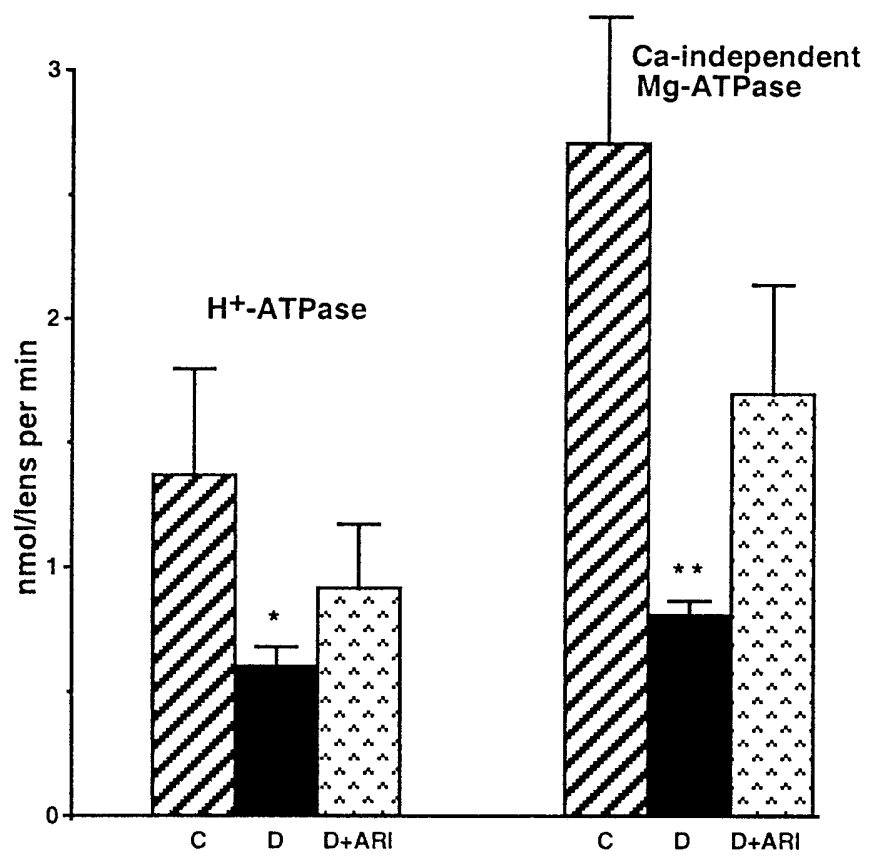

Fig. 2. Lens $\mathrm{H}^{+}$-ATPase and $\mathrm{Ca}^{++}$-independent $\mathrm{Mg}^{++}$-stimulated ATPase activities in control (C) and diabetic (D) rats treated with or without ARI (means \pm SEM, $n=7-10)$. ***; significantly different vs controls ( $p<0.05$ and $<0.01$, respectively).

Malondialdehyde plus 4-HA and MDA concentrations were 3.9-fold and 5.3-fold higher in diabetic rats than in controls (Fig. 3). Malondialdehyde concentration was 2-fold reduced, but not normalized, by the ARI treatment. MDA plus 4-HA concentration tended to decrease, due to reduced accumulation of

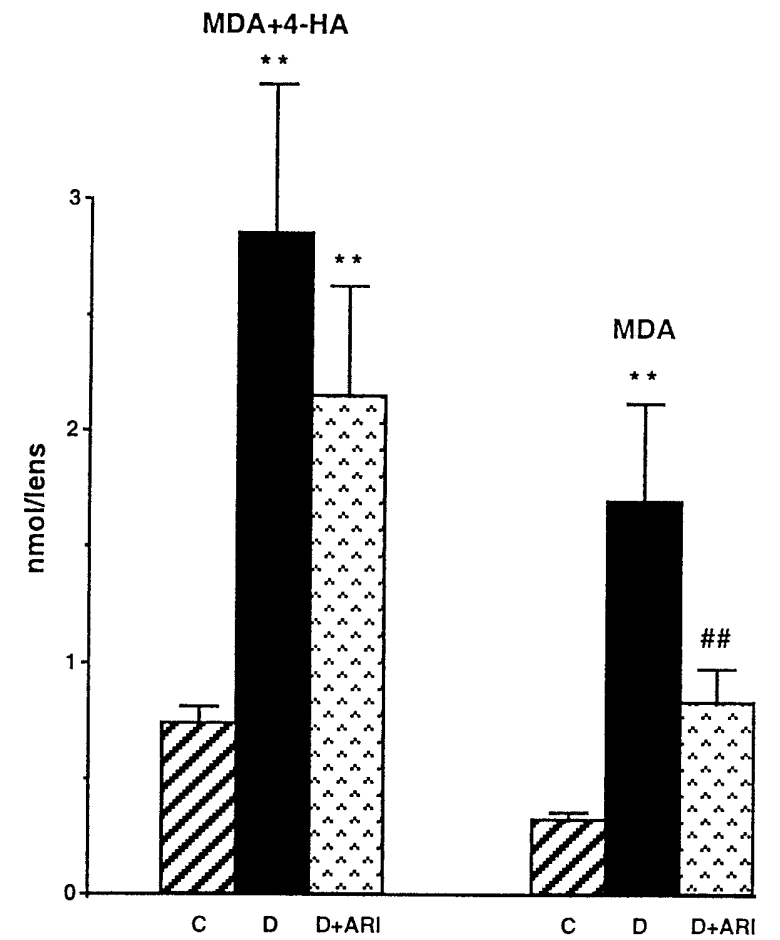

Fig. 3. Lens total MDA plus 4-HA and MDA concentrations in control (C) and diabetic (D) rats treated with or without ARI (means \pm SEM, $n=6-8$ ). **; significantly different vs controls $(p<0.01)$. \#\#; significantly different vs untreated diabetic group $(p<0.01)$

MDA, but not 4-HA, in the ARI-treated rats. The difference with the untreated diabetic group did not, however, achieve statistical significance.

Lens GSH concentration was decreased 3.5-fold in diabetic rats compared with controls, whereas GSSG concentrations and the GSSG:GSH ratio were increased 2.5-fold and 12.2-fold (Fig. 4). Reduced glutathione concentration was increased, but not normalized, by the ARI treatment. Oxidized glutathione concentration tended to decrease being not significantly different from either the untreated diabetic group or controls. The GSSG:GSH ratio was 2.9-fold lower in ARI-treated diabetic rats than in untreated diabetic groups but was still 4.2-higher than in controls.

\section{Discussion}

The 2-week sorbinil treatment, started after 4 weeks of untreated diabetes, effectively inhibited increased sorbitol pathway activity in diabetic precataractous lens. Sorbitol and fructose accumulation was corrected by $99 \%$ and $94 \%$, respectively. The higher efficacy of ARIs in correcting sorbitol compared with fructose accumulation has been reported for several tissues $[37,38]$ and suggests that, in addition to the sorbitol dehydrogenase (SDH) reaction, fructose can be 

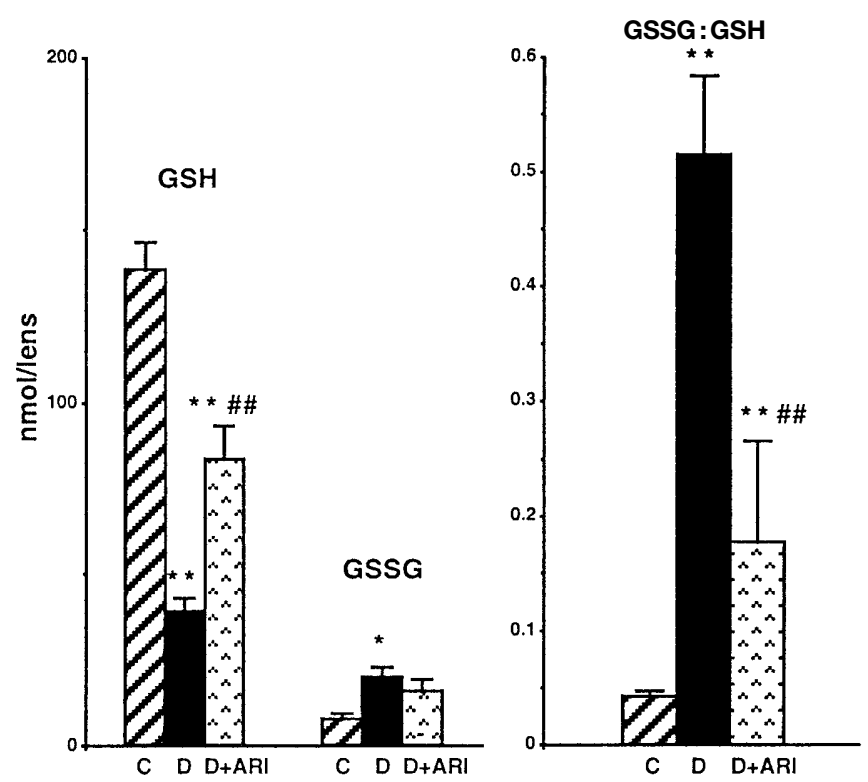

Fig. 4 A, B. Lens GSH and GSSG concentrations (A) and GSSG:GSH ratios (B) in control (C) and diabetic (D) rats treated with or without ARI (means \pm SEM, $n=6-8)$. ***; significantly different vs controls $(p<0.05$ and $<0.01$, respectively). \#\#, significantly different vs untreated diabetic group $(p<0.01)$

formed in other pathways, e.g. by dephosphorylation of the glycolytic product, fructose 6-phosphate.

The short-term treatment with an adequate dose of ARI seemed sufficient to correct diabetes-induced decrease in the free cytosolic $\mathrm{NAD}^{+}: \mathrm{NADH}$ ratio. This is consistent with prevention studies in both diabetic [39] and galactose-fed [5] rats. The correction is probably mediated through decreased lipid peroxidation and inhibition of SDH activity. Our studies with $5 \%$ taurine supplementation [31] and SDH inhibitor [27] showed that both oxidative stress and increased flux through SDH are involved in the shift towards a more reduced state of free cytosolic NAD-couple in the diabetic lens.

The diabetes-induced increase in free cytosolic $\mathrm{NADP}^{+}$:NADPH was not affected by the ARI treatment. The latter is the most surprising because increased accumulation of the sorbitol pathway intermediates, an indicator of NADPH consumption by AR, was essentially corrected. The lens free cytosolic $\mathrm{NADP}^{+}: \mathrm{NADPH}$ ratio is, however, maintained, in addition to AR, by at least seven enzymes, i.e. NADP-dependent glucose 6-phosphate $[40,41]$ and 6-phosphogluconate $[40,42]$ dehydrogenases, malic enzyme [43], isocitrate dehydrogenase [43] and NADPH-dependent glutathione reductase [44, 45], NAD(P)H-oxidase [46] and NADPH-diaphorase [47]. The post-translational regulation of the abovementioned enzymes in the lens, with the exception of glucose 6-phosphate dehydrogenase [40, 41], has not been studied in detail.
The diabetes-induced decrease in ATP concentration, ATP:ADP ratio and adenylate energy charge were corrected by short-term ARI treatment. This agrees with the early findings [48] showing a role for polyol accumulation and resulting osmotic stress in diabetes-induced decay of lens ATP and later reports of prevention of lens energy failure with AR inhibition in both diabetic [4] and galactosaemic [5] rats.

The mechanisms underlying decreased $\mathrm{Na}^{+} / \mathrm{K}^{+}$ATPase pumping activity in sites for diabetic complications are not clear. One concept implies that diabetes-induced myo-inositol depletion, followed by disturbances in phosphoinositide turnover, interferes with the normal structural and functional properties of plasma membranes and is ultimately responsible for down-regulation of $\mathrm{Na}^{+} / \mathrm{K}^{+}$-ATPase [49]. Other findings [50] dissociate decreased $\mathrm{Na}^{+} / \mathrm{K}^{+}$-ATPase pumping activity and myo-inositol depletion in diabetic tissues. The preservation of diminished total, ouabain-insensitive and ouabain-sensitive $\mathrm{Na}^{+} / \mathrm{K}^{+}-$ ATPase activities despite the complete normalization of lens myo-inositol concentrations in the ARI-treated diabetic rats in our study is consistent with the lack of close association between $\mathrm{Na}^{+} / \mathrm{K}^{+}$-pump function and myo-inositol abundance. The modulation of $\mathrm{Na}^{+} / \mathrm{K}^{+}$-ATPase activity by oxidative stress [51], C peptide [52], ATP depletion [53], nerve growth factor [54], protein kinase $\mathrm{C}$ inhibitor [55], thrombin [56] and endothelin-1 [57] reflects the complex regulation of this enzyme. Despite this complexity, the diabetesinduced down-regulation of $\mathrm{Na}^{+} / \mathrm{K}^{+}$-ATPase is, however, completely prevented by structurally different ARIs [29, 58]. There must be some component(s) in the enzyme regulation that undergoes irreversible, at least by the short-term ARI treatment, changes in the diabetic lens.

The relation between AR and oxidative stress is still the controversial area. Numerous reports indicate that the effects of ARIs and antioxidants are unidirectional and that both types of agents prevent or delay diabetic cataract $[1,3,16,59,60]$, neuropathy $[1,17,61]$, retinopathy $[1,15,18,19,24,62]$ and nephropathy $[1,63]$. Conversely, some recent studies [64] suggest that AR, which metabolises the most toxic products of lipid peroxidation, 4-HA, protects from the development of diabetic complications. The findings of exacerbation of diabetes-induced lipid peroxidation and glutathione depletion with overexpression of the gene coding for AR protein in the lens [7] as well as the arrest of MDA and 4-HA accumulation by structurally different ARIs $[8,30]$ indicate, however, that increased AR activity results in, rather than protects from, oxidative injury in tissue sites for diabetic complications. This is supported by this intervention study showing the decrease, but not normalization, of MDA accumulation in ARI-treated rats compared with the untreated diabetic group. In contrast to the observations in the diabetic kidney [64], 
sorbinil did not stimulate additional accumulation of 4-HA in the diabetic lens.

The decreased accumulation of lipid peroxidation products is consistent with the higher GSH concentration and the lower GSSG:GSH ratio in the ARItreated diabetic rats compared with the untreated group. Our findings are consistent with numerous reports of prevention of diabetes-induced GSH depletion with ARI treatment $[6,8,30]$. The studies of our group and others with both ARI [8] and SDH inhibitor $[27,65]$ suggest that sorbitol accumulation and resulting osmotic stress, rather than AR-mediated NADPH deficiency and associated slowing of the glutathione redox cycle, non-enzymatic glycation of glutathione reductase or enzymes of GSH biosynthesis or $\mathrm{NAD}^{+}: \mathrm{NADH}$ redox changes, are responsible for the loss of non-enzymatic antioxidants and increased lipid peroxidation in the diabetic rat lens. The osmotic origin of oxidative stress is, however, not supported by findings in the diabetic SDH-deficient mice that contained lower MDA and higher GSH concentrations in the lens than the diabetic mice with normal SDH activity [7]. Because of these interspecies differences, the mechanisms, underlying exacerbation of lenticular oxidative stress under conditions of increased AR activity in humans [66], require specific studies.

Recently, one group of investigators [67] suggested that oxidative stress is a cause rather than a consequence of increased AR activity and that sorbitol accumulation is downstream from oxidative stress in the pathogenesis of diabetic complications. This concept is not supported by the findings of our group [8, $26,31]$ and others $[68,69]$. In particular, the potent antioxidant DL- $\alpha$-lipoic acid effectively counteracted oxidative stress in the diabetic lens [26], peripheral nerve $[8,61]$ and retina [70] but did not decrease accumulation of the sorbitol pathway intermediates in any of these tissues. Intralenticular sorbitol and fructose concentrations were not affected by taurine which decreased lens MDA accumulation about twofold compared with the untreated diabetic group [31]. Butylated hydroxytoluene [68] and probucol [69] have been found ineffective on the sorbitol pathway intermediates in the diabetic nerve. These findings, together with the afore-mentioned reports of exacerbation of lipid peroxidation with overexpression of the gene coding for AR protein [7] and prevention or correction of tissue oxidative stress by ARIs [6, 8], clearly indicate that increased AR activity is a cause, but not a consequence, of oxidative stress in sites for diabetic complications.

All diabetes-induced metabolic changes in the lens, assessed in our study, are known to be prevented by ARIs. Despite the essential normalization of the sorbitol pathway activity, only part of them was, however, reversed by the ARI treatment introduced at the very early, i.e. precataractous, stage of diabetes. It is not clear from our study if "the point of no return" occurs as early as at the precataractous stage of diabetes or longer sorbinil treatment would correct the whole spectrum of biochemical abnormalities in the lens. It is, however, obvious that the intervention approach alone, especially with suboptimal doses of ARIs applied so far in clinical trials, can easily underestimate the importance of AR in the pathogenesis of diabetic complications. The only clinical trial of ARIs on diabetic ocular complications, i.e. sorbinil retinopathy trial [21], included patients with microaneurysms on both eyes treated with a relatively low dose of sorbinil.

Acknowledgements. The authors thank C.M. Stockert for help in preparation of the manuscript.

\section{References}

1. Kador PF (1988) The role of aldose reductase in the development of diabetic complications. Med Res Rev 8: 325-352

2. Burg MB (1995) Molecular basis of osmotic regulation. Am J Physiol 268: F983-F996

3. Chylack LT Jr, Friend J (1990) Intermediary metabolism of the lens: a historical perspective 1928-1989. Exp Eye Res 50: $575-582$

4. Tsubota K, Yoshida M, Toda T, Ono M, Kajiwara K, Cheng HM (1993) Aldose reductase inhibition and the phosphorus-31 profile of the intact diabetic rat. Ophthalmic Res 25: 393-399

5. Obrosova I, Faller A, Burgan J, Ostrow E, Williamson JR (1997) Glycolytic pathway, redox state of NAD(P)-couples and energy metabolism in lens in galactose-fed rats: effect of an aldose reductase inhibitor. Curr Eye Res 16: 34-43

6. Lou MF, Dickerson JE Jr, Garadi R, York BM Jr (1988) Glutathione depletion in the lens of galactosemic and diabetic rats. Exp Eye Res 46: 517-530

7. Lee AY, Chung SS (1999) Contribution of polyol pathway to oxidative stress in diabetic cataract. FASEB J 13: 23-30

8. Obrosova IG, Greene DA, Lang HJ (2000) Antioxidative Defense in Diabetic Peripheral Nerve: Effects of DL- $\alpha$-Lipoic Acid, Sorbitol Dehydrogenase Inhibitor and Aldose Reductase Inhibitor. In: Packer L, Rosen P, Tritschler HJ, King GL, Azzi A (eds) Antioxidants in Diabetes Management, Marcel Dekker, New York, pp 93-110

9. Keogh RJ, Dunlop ME, Larkins RG (1997) Effect of inhibition of aldose reductase on glucose flux, diacylglycerol formation, protein kinase $\mathrm{C}$, and phospholipase $\mathrm{A} 2$ activation. Metabolism 46: 41-47

10. Ishii H, Tada H, Isogai $S(1998)$ An aldose reductase inhibitor prevents glucose-induced increase in transforming growth factor-beta and protein kinase $\mathrm{C}$ activity in cultured mesangial cells. Diabetologia 41: 362-364

11. Nagaraj RH, Prabhakaram M, Ortwerth BJ, Monnier VM (1994) Suppression of pentosidine formation in galactosemic rat lens by an inhibitor of aldose reductase. Diabetes 43: 580-586

12. Tsukushi S, Katsuzaki T, Aoyama I et al. (1999) Increased erythrocyte 3-DG and AGEs in diabetic hemodialysis patients: role of the polyol pathway. Kidney Int 55: 1970-1976

13. Mizisin AP, Calcutt NA, DiStefano PS, Acheson A, Longo FM (1997) Aldose reductase inhibition increases CNTFlike bioactivity and protein in sciatic nerves from galactose-fed and normal rats. Diabetes 46: 647-652 
14. Ohi T, Saita K, Furukawa S, Ohta M, Hayashi K, Matsukura S (1998) Therapeutic effects of aldose reductase inhibitor on experimental diabetic neuropathy through synthesis/secretion of nerve growth factor. Exp Neurol 151: 215-220

15. Frank RN, Amin R, Kennedy A, Hohman TC (1997) An aldose reductase inhibitor and aminoguanidine prevent vascular endothelial growth factor expression in rats with long-term galactosemia. Arch Ophthalmol 115: 1036-1047

16. Kador PF, Akagi Y, Kinoshita JH (1985) Diabetic cataracts in animal models: prevention and reversibility with aldose reductase inhibitors. Diabet Med 2: 194-196

17. Cameron NE, Cotter MA, Basso M, Hohman TC (1997) Comparison of the effects of inhibitors of aldose reductase and sorbitol dehydrogenase on neurovascular function, nerve conduction and tissue polyol pathway metabolites in streptozotocin-diabetic rats. Diabetologia 40: 271-281

18. Kador PF, Takahashi Y, Sato S, Wyman M (1994) Amelioration of diabetes-like retinal changes in galactose-fed dogs. Prev Med 23: 717-721

19. Neuenschwander H, Takahashi Y, Kador PF (1997) Dosedependent reduction of retinal vessel changes associated with diabetic retinopathy in galactose-fed dogs by the aldose reductase inhibitor M79 175. J Ocul Pharmacol Ther 13: 517-528

20. Pfeifer MA, Schumer MP, Gelber DA (1997) Aldose reductase inhibitors: the end of an era or the need for different trial designs? Diabetes 46 [Suppl 2]: S82-S89

21. Anonymous (1990) A randomized trial of sorbinil, an aldose reductase inhibitor, in -fed diabetic retinopathy. Sorbinil Retinopathy Trial Research Group. Arch Ophthalmol 108: $1234-1244$

22. Obrosova I, Van Huysen C, Fathallah L, Stevens MJ, Cao X, Greene DA (1999) Evaluation of an ARI on diabetic nerve function, metabolism and antioxidant status: an intervention study. Diabetologia 42 [Suppl 1] A43 (Abstract)

23. Robison WG Jr, Laver NM, Jacot JL, Chandler ML, York BM, Glover JP (1997) Efficacy of treatment after measurable diabetic like retinopathy in galactose-fed rats. Invest Ophthalmol Vis Sci 38: 1066-1073

24. Robison WG Jr, Jacot JL, Glover JP, Basso MD, Hohman TC (1998) Diabetic-like retinopathy: early and late intervention therapies in galactose-fed rats. Invest Ophthalmol Vis Sci 39: 1933-1941

25. Kador PF, Inoue J, Secchi EF et al. (1998) Effect of sorbitol dehydrogenase inhibition on sugar cataract formation in galactose-fed and diabetic rats. Exp Eye Res 67: 203-208

26. Obrosova I, Cao X, Greene DA, Stevens MJ (1998) Diabetes-induced changes in lens antioxidant status, glucose utilization and energy metabolism: effect of DL- $\alpha$-lipoic acid. Diabetologia 41: 1442-1450

27. Obrosova IG, Fathallah L, Lang HJ (1999) Interaction between osmotic and oxidative stress in diabetic precataractous lens. Studies with a sorbitol dehydrogenase inhibitor. Biochem Pharmacol 58: 1945-1954

28. Kuriyama H, Sasaki K, Fukuda M (1983) Studies on diabetic cataract in rats induced by streptozotocin. II. Biochemical examinations of rat lenses in relation to cataract stages. Ophthalmic Res 15: 191-197

29. Beyer-Mears A, Mistry K, Diecke FP, Cruz E (1996) Zopolrestat prevention of proteinuria, albuminuria and cataractogenesis in diabetes mellitus. Pharmacology 52: 292-302

30. Saito H (1995) Biochemical changes in lens, aqueous humor and vitreous body and effects of aldose reductase inhibitor (TAT) on rat with experimental diabetes. Nippon Ika Daigaku Zasshi 62: 339-350
31. Obrosova IG, Stevens MJ (1999) Effect of dietary taurine supplementation on GSH and NAD(P)-redox status, lipid peroxidation, and energy metabolism in diabetic precataractous lens. Invest Ophthalmol Vis Sci 40: 680-688

32. Erdelmeier I, Gerard-Monnier D, Yadan JC, Chaudiere J (1998) Reactions of N-methyl-2-phenylindole with malondialdehyde and 4-hydroxyalkenals. Mechanistic aspects of the colorimetric assay of lipid peroxidation. Chem Res Toxicol 11: 1184-1194

33. Lowry OH, Passonneau JV (1972) A Flexible System of Enzymatic Analysis. Academic Press, Orlando

34. Williamson JH, Lund P, Krebs HA (1967) The redox state of free nicotinamide-adenine dinucleotide in the cytoplasm and mitochondria of rat liver. Biochem J 103: 514-527

35. Veech RL, Eggleston LV, Krebs HA (1967) The redox state of free nicotinamide-adenine nucleotide phosphate in the cytoplasm of rat liver. Biochem J 115: 609-619

36. Guerrieri F, Yagi A, Yagi T, Papa S. (1984) On the mechanism of $\mathrm{H}^{+}$Translocation by Mitochondrial $\mathrm{H}+$-ATPase. Studies with Chemical Modifier of Tyrosine Residues. J Bioenerg Biomembr 16: 251-262

37. Poulsom R, Boot-Handford RP, Heath H (1983) The effects of long-term treatment of streptozotocin-diabetic rats with an aldose reductase inhibitor. Exp Eye Res 37: 507-515

38. Ramasamy R, Oates PJ, Schaefer S (1997) Aldose reductase inhibition protects diabetic and nondiabetic rat hearts from ischemic injury. Diabetes 46: 292-300

39. Gonzalez AM, Sochor M, Hothersall JS, McLean P (1986) Effect of aldose reductase inhibitor (sorbinil) on integration of polyol pathway, pentose phosphate pathway, and glycolytic route in diabetic rat lens. Diabetes 35: $1200-1205$

40. Cheng HM, Chylack LT Jr (1977) Regulation and stabilization of lens glucose-6-phosphate dehydrogenase. Exp Eye Res 24: 459-466

41. Rao P, Ziegler JS Jr (1992) Quinone induced stimulation of hexose monophosphate shunt activity in the guinea pig lens: role of zeta-crystallin. Biochim Biophys Acta 1116: $75-81$

42. Ganea E, Harding HJ (1996) Inhibition of 6-phosphogluconate dehydrogenase by carbamylation and protection by alpha-crystallin, a chaperone-like protein. Biochem Biophys Res Commun 222: 626-631

43. Winkler BS, Solomon F (1988) High activities of NADP + -dependent isocitrate dehydrogenase and malic enzyme in rabbit lens epithelial cells. Invest Ophthalmol Vis Sci 29: $821-833$

44. Reddan JR, Giblin FJ, Dziedzic DC, McCready JR, Schrimscher L, Reddy VN (1988) Influence of the activity of glutathione reductase on the response of cultured lens epithelial cells from young and old rabbits to hydrogen peroxide. Exp Eye Res 46: 209-221

45. Wang GM, Raghavachari N, Lou MF (1997) Relationship of protein-glutathione mixed disulfide and thioltransferase in $\mathrm{H} 2 \mathrm{O} 2$-induced cataract in cultured pig lens. Exp Eye Res 64: 693-700

46. Haraguchi H, Ohmi I, Kubo I (1996) Inhibition of aldose reductase by maesanin and related $p$-benzoquinone derivatives and effects on other enzymes. Bioorg Med Chem 4: 49-53

47. Chen Z, Gu Q, Kaufman PL, Cynader MS (1998) Histochemical mapping of NADPH-diaphorase in monkey and human eyes. Curr Eye Res 17: 370-379

48. Kinoshita J (1974) Mechanisms initiating cataract formation. Invest Ophthalmol 13: 713-724

49. Greene DA, Lattimer SA (1984) Action of sorbinil in diabetic peripheral nerve: relationship of polyol (sorbitol) 
pathway inhibition to a myo-inositol-mediated defect in sodium-potassium ATPase activity. Diabetes 33: 712-716

50. Yeh LA, Rafford CE, Goddu KJ, Ashton MA, Beyer TA, Hutson NJ (1987) $\mathrm{Na}^{+}-\mathrm{K}^{+}$-ATPase Pumping Activity Is Not Directly Linked to myo-Inositol Levels After Sorbinil Treatment in Lenses of Diabetic Rats. Diabetes 36: 1414-1419

51. Szabo C (1996) The pathophysiological role of peroxynitrite in shock, inflammation, and ischemia-reperfusion injury. Shock 6: 79-88

52. De La Tour DD, Raccah D, Jannot MF, Coste T, Rougerie C, Vague P (1998) Erythrocyte Na/K ATPase activity and diabetes: relationship with C-peptide level. Diabetologia 41: 1080-1084

53. Kuwahara S, Chin S, Delamere NA (1998) Partial inhibition of Na,K-ATPase activity in cultured rabbit non-pigmented ciliary epithelium following an episode of cytoplasmic ATP depletion. Acta Physiol Scand 164: 13-20

54. Kurihara K, Hosoi K, Ueha T, Nakanishi N, Yamada S (1994) Effects of nerve growth factor and dexamethasone on $\mathrm{Na}(+), \mathrm{K}(+)$-ATPase of cultured PC12 h cells. Horm Metab Res 26: 14-18

55. Cameron NE, Cotter MA, Jack AM, Basso MD, Hohman TC (1999) Protein kinase C effects on nerve function, perfusion, $\mathrm{Na}(+), \mathrm{K}(+)$-ATPase activity and glutathione content in diabetic rats. Diabetologia 42: 1120-1130

56. Okafor MC, Dean WL, Delamere NA (1999) Thrombin inhibits active sodium-potassium transport in porcine lens. Invest Ophthalmol Vis Sci 40: 2033-2038

57. Delamere NA, Okafor M, Dean WL (1999) Inhibition of the porcine lens sodium pump by endothelin. Ophthalmic Res 31 [Suppl 1] 105 (Abstract)

58. Mizuno K, Kato N, Matsubara A, Nakano K, Kurono M (1992) Effects of a new aldose reductase inhibitor, (2S, 4S)-6-fluoro-2',5'-dioxospiro[chroman-4,4'-imidazolidine]2-carboxamide (SNK-860), on the slowing of motor nerve conduction velocity and metabolic abnormalities in the peripheral nerve in acute streptozotocin-induced diabetic rats. Metabolism 41: 1081-1086

59. Ansari NH, Srivastava SK (1990) Allopurinol promotes and butylated hydroxy toluene prevents sugar-induced cataractogenesis. Biochem Biophys Res Commun 168: 939-943
60. Kilic F, Mitton K, Dzialoszynski T, Sanford SE, Trevithick JR (1994) Modelling cortical cataractogenesis. 14: Reduction in lens damage in diabetic rats by a dietary regimen combining vitamins $\mathrm{C}$ and $\mathrm{E}$ and beta-carotene. Dev Ophthalmol 26: 63-71

61. Low PA, Nickander KK, Tritschler HJ (1997) The roles of oxidative stress and antioxidant treatment in experimental diabetic neuropathy. Diabetes 46 [Suppl 2]: S38-S42

62. Ansari NH, Zhang W, Fulep E (1998) Prevention of pericyte loss by trolox in diabetic rat retina. J Toxicol Environ Health 54: 467-475

63. Trachtman H, Futterweit S, Maesaka J et al. (1995) Taurine ameliorates chronic streptozocin-induced diabetic nephropathy in rats. Am J Physiol 269: F429-F438

64. Rittner HL, Hafner V, Klimiuk PA, Szweda LI, Goronzy JJ, Weyand CM (1999) Aldose reductase functions as a detoxification system for lipid peroxidation products in vasculitis. J Clin Invest 103: 1007-1013

65. Obrosova IG, Fathallah L, Lang HJ, Greene DA (1999) Evaluation of a sorbitol dehydrogenase inhibitor on diabetic peripheral nerve metabolism: a prevention study. Diabetologia 42: 1187-1194

66. Reddy VN, Lin LR, Giblin FJ, Chakrapani B, Yokoyama T (1992) Study of the polyol pathway and cell permeability changes in human lens and retinal pigment epithelium in tissue culture. Invest Ophthalmol Vis Sci 33: 2334-2339

67. Brownlee MA, Nishikawa T, Edelstein D, Giardino I, Beebe D, Oates PJ (1999) Reversal of hyperglycemia-induced PKC activation, intracellular AGE formation, and sorbitol accumulation by inhibition of electron transport complex II. Diabetes 48 [Suppl.1] A73 (Abstract)

68. Cameron NE, Cotter MA, Maxfield EK (1993) Anti-oxidant treatment prevents the development of peripheral nerve dysfunction in streptozotocin-diabetic rats. Diabetologia 36: 299-304

69. Cameron NE, Cotter MA, Archibald V, Dines KC, Maxfield EK (1994) Anti-oxidant and pro-oxidant effects on nerve conduction velocity, endoneurial blood flow and oxygen tension in non-diabetic and streptozotocin-diabetic rats. Diabetologia 37: 449-459

70. Obrosova IG, Fathallah L, Greene DA (2000) Early changes in lipid peroxidation and antioxidative defense in diabetic rat retina: effect of DL- $\alpha$-lipoic acid. Eur J Pharmacol (in press) 